\title{
0884 QUALITY INDICATORS FOR TRAUMA REGISTRIES - TOWARDS AGREEMENT ON A WORLD WIDE STANDARD?
}

J M Lauritsen*, K G Ringdal Correspondence: Odense University Hospital, Accident Analysis Group, Sdr Boulevard 29 Odense, DK5000 C, Denmark

\subsection{6/ip.2010.029215.884}

Worldwide, approximately 5 million persons died as a result of an injury in 2000 worlds burden of disease. Almost $50 \%$ of the worlds injury-related mortality occurs in young people aged between 15 and 44 years, the most economically productive members of the global population. Trauma registries constitute a major source for research on injury prevention (primary prevention), and enables comparative analyses of trauma care and outcome to provide quality improvements in trauma care (secondary prevention). However no agreed common set of defined quality indicators have been published for genera ${ }^{1}$ use across continents. In 2007, an expert panel consisting of representatives from major trauma organisations in Europe created the Utstein Trauma Template, a European minimum core dataset and definitions for documenting and reporting data on severely injured patients, containing patient factors, operational factors and system factors. Trauma registries across Europe have agreed to implement this dataset. To make proper evaluations of trauma care an agreed set of quality indicators must be created. It is the purpose of this workshop to start an open process of defining a minimal set of quality indicators for evaluation of trauma care. Trauma registries, trauma organisations as well as trauma interested clinicians and researchers 
are suggested to take part in an open discussion. In extension of the workshop a postconference process leading to publication of a suggested set of quality indicators is envisioned.

\section{Reference}

1. Ringdal KJ et al. The Utstein trauma template for reporting of data following major trauma: European trauma registry network 2008. Scandinavian Journal of Trauma, Resuscitation and Emergency Medicine 2008;16:7. 